\title{
Predicting survival in cystic fibrosis
}

\author{
D J Shale
}

There is a continuing increase worldwide in the survival of patients with cystic fibrosis. In the United Kingdom the median age of survival is approximately 31 years and rising. Estimates based on the previous rate of improvement of survival, and current figures which support those predictions, suggest that patients born in this decade will have a median survival beyond 40 years. ${ }^{1}$ For populations of patients these measures are easy to determine, but for individual patients prediction of survival can be difficult.

Previous studies have suggested that a range of clinical variables, often collected routinely, may have a predictive value that can be used with a degree of certainty. ${ }^{2-4}$ The problem for the clinician dealing with an individual patient is that published studies of survival are often related to a single centre, a different population, possibly with varying age groups, a study design that is inapplicable to their own practice, and a different pattern of health care delivery. ${ }^{2-4}$

In an early study of the prediction of survival beyond the age of 18 years based on 142 patients observed over a mean period of 14.5 years, the best predictor of five year survival was the Shwachman score. This may reflect the fact that the study was in young people where this scoring system seems to have most value. A poor prognosis was associated with infection with Burkholderia cepacia, a low weight centile, and a low clinical score. A good prognosis was associated with the reverse of these variables and the presence of pancreatic sufficiency. Birth weight, the age of diagnosis, age at onset of symptoms, and first attendance at a cystic fibrosis centre had no relationship to survival beyond 18 years. $^{2}$

Advances in transplantation offer the patient a range of double lung, heart/lung and, occasionally, heart/liver/lung transplantation. Optimising the timing of transplantation depends on referring physicians being able to make an accurate prediction of relatively short term survival. Failure to get the timing right for the individual patient may lead to unnecessary suffering and unhappiness both for the patients and their families.

In an attempt to predict one to two year survival, changes in the pulmonary function tests, arterial blood gas tensions, and the nutritional status of 673 patients over a 10 year period were used to develop a statistical statement of outcome. A $>50 \%$ mortality over a two year period was associated with a forced expiratory volume in one second $\left(\mathrm{FEV}_{1}\right)<30 \%$ predicted, and arterial oxygen and carbon dioxide tensions of $<7.3 \mathrm{kPa}$ and $>6.6 \mathrm{kPa}$, respectively. Age and sex were also predictors and, when corrected for this, the relative risk was 2.0 for each $10 \%$ fall below the predicted $\mathrm{FEV}_{1}$, with a relative risk of 2.2 for females. ${ }^{3} \mathrm{An}$ $\mathrm{FEV}_{1}$ of $<30 \%$ predicted has been widely used as a yardstick for predicting a crude two year survival in patients with cystic fibrosis.

The difficulties of general application of studies to routine practice are highlighted by an exercise study in children followed over an eight year period. Here, preservation of aerobic fitness was an excellent predictor of survival but, in contrast to other studies, this group of 109 children showed no independent associations between survival, $\mathrm{FEV}_{1}$, age, sex, or nutritional status. ${ }^{4}$

What is still required is a statistically robust prognostic model to help the physician in making decisions related to an assessment of survival for an individual patient. In this issue of Thorax Hayllar and colleagues ${ }^{5}$ publish details of a prognostic tool that allows the prediction of short term survival in patients with cystic fibrosis. They reviewed routine clinical data collected prospectively on 403 patients over an 18 year period and analysed them by log rank and univariate Cox regression analysis to determine which variables predicted survival. The variables of prognostic value were the $\%$ predicted $\mathrm{FEV}_{1}, \%$ predicted forced vital capacity (FVC), short stature, a raised white blood cell count, and chronic liver disease based on the presence of hepatomegaly. These variables, complete only for 373 patients, were then subjected to a time dependent multivariate Cox regression analysis to generate a prognostic model. The model of survival was validated in a $25 \%$ sample of the study population and further validated in a cohort of 100 patients recruited after 1988, and accurate predictions of one year survival were obtained in both of the validation studies.

The importance of this approach over that of earlier ones is the pooling of multiple variables to generate a model for prediction based on the underlying risk of death at any given time. This hazard function appeared to be fairly constant. The variables used in the generation of the model are clinical data which are already routinely collected in major centres and are likely to be collected in all centres of whatever size as guidelines of care are implemented. In addition, the study is based largely on adolescent and adult patients and reflects the group where better prediction of short term outcome would be of great value and possibly improve the timing of transplantation procedures.

So far, this methodology has been limited to generating a one year prognosis for patients at a single centre. It is hoped that further studies will show that this is a robust model and may be of value in predicting prognosis in other cohorts of patients with cystic fibrosis.

Section of Respiratory Medicine,

D J SHALE

University of Wales
Llandough Hospital,

Penarth,

South Glamorgan CF6 $1 \mathrm{XX}$, UK

1 Elborn JS, Shale DJ, Britton JR. Cystic fibrosis: current survival and population estimates to the year 2000. Thorax 1991;46:881-5.

2 Huang NN, Schidlow DV, Szatrowski TH, Palmer J, Laray-Cuasay LR, Yeung W, et al. Clinical features, survival rate and prognostic factors in young adults with cystic fibrosis. Am $\mathcal{F}$ Med 1987;82:871-9.

3 Kerem E, Reisman J, Corey M, Canny GJ, Levison H. Prediction of mortality in patients with cystic fibrosis. N Engl F Med 1992;326:1187-91.

4 Nixon PA, Orenstein DM, Kelsey SF, Doershuk CF. The prognostic value of exercise testing in patients with cystic fibrosis. $N$ Engl f Med 1992;327: $1785-8$.

5 Hayllar KM, Williams SGJ, Wise AE, Pouria S, Lombard M, Hodson ME, et al. A prognostic model for the prediction of survival in cystic fibrosis. Thorax 1997;52:313-7. 